\title{
A Comparative Study: Autologous Blood donation with Normovolemic Haemodilution in a Tertiary Cardiac Unit, UK
}

\author{
Kalamkar Y. ${ }^{1}$, Jeeji R. ${ }^{1}$, Mehta V. ${ }^{1}$, Butterworth G. ${ }^{1}$, Balacumaraswami L. ${ }^{2}$ \\ ${ }^{1}$ Dept. of Anaesthesiology and Intensive Care, ${ }^{2}$ Dept.of Cadio-thoracic Surgery \\ University Hospitals of North Midlands NHS Trust, United Kingdom
}

Background: It is estimated that cardiac surgical units utilise about $4 \%$ of all red cell transfusions. [1] The national blood transfusion audit (NBA) reveals wide variation in transfusion rates and product usage between units. [2] Autologous Blood Donation (ABD) with normovolemic haemodilution is an established strategy for blood conservation.

Method: In this retrospective study, we included 156 patients who underwent cardiac surgery were included. Equal number of elective and emergency surgeries were included. Normovolaemic haemodilution was performed with one unit of autologous blood $(500 \mathrm{ml})$ collected via a PA sheath under all asepsis before skin incision in ABD group. Autologous blood was reinfused after heparin reversal. Anonymised data were collected from a theatre management system, patient's anaesthetic notes and transfusion databases. Comparison was made with the NBA.

Results: A total of 156 patients were analysed. The largest procedure groups were coronary artery bypass grafts (CABG) on-pump and off pump, followed by aortic valve surgery and single valve with $\mathrm{CABG}$ procedures. The gross transfusion rates for packed red cells (PRC), fresh frozen plasma (FFP), cryoprecipitate (Cryo) and platelets (Plt) were 15.3\%, 6.4\%, $5.1 \%$ and $2.5 \%$ in $\mathrm{ABD}$ group and $69.2 \%, 47.4 \%, 62.8 \%$ and $56.4 \%$ in Non-Autologous transfusion group respectively. National Comparative Audit of blood transfusion 2011 shows that the average rate transfusion rate of $43 \%$ for Packed red cells, $13 \%$ for FFP and 15\% Platelets. Blood transfusion rate in all patients on-pump and off pump, elective and non-elective $\mathrm{CABG}$ is $42 \%$ in our centre.

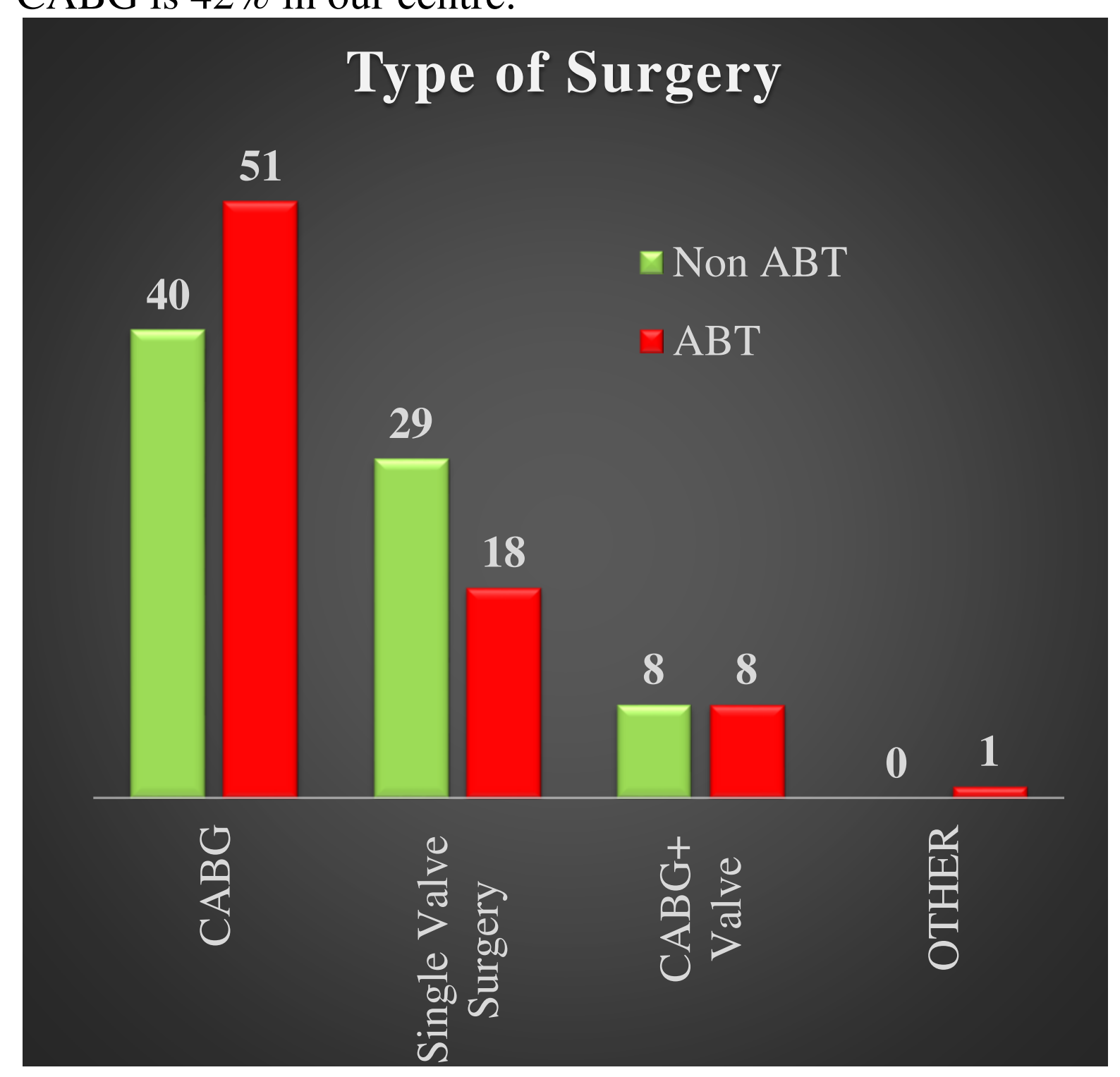

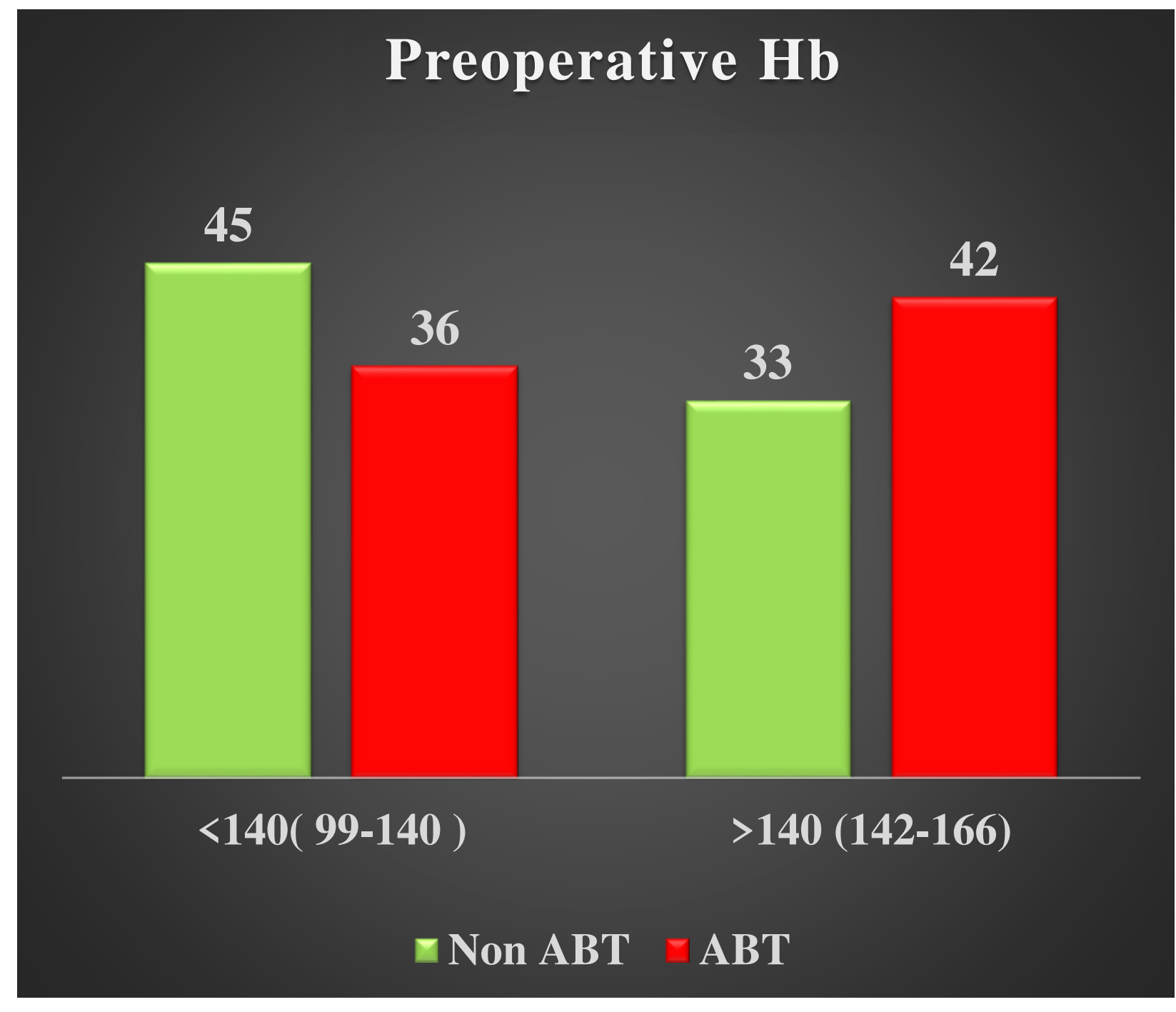

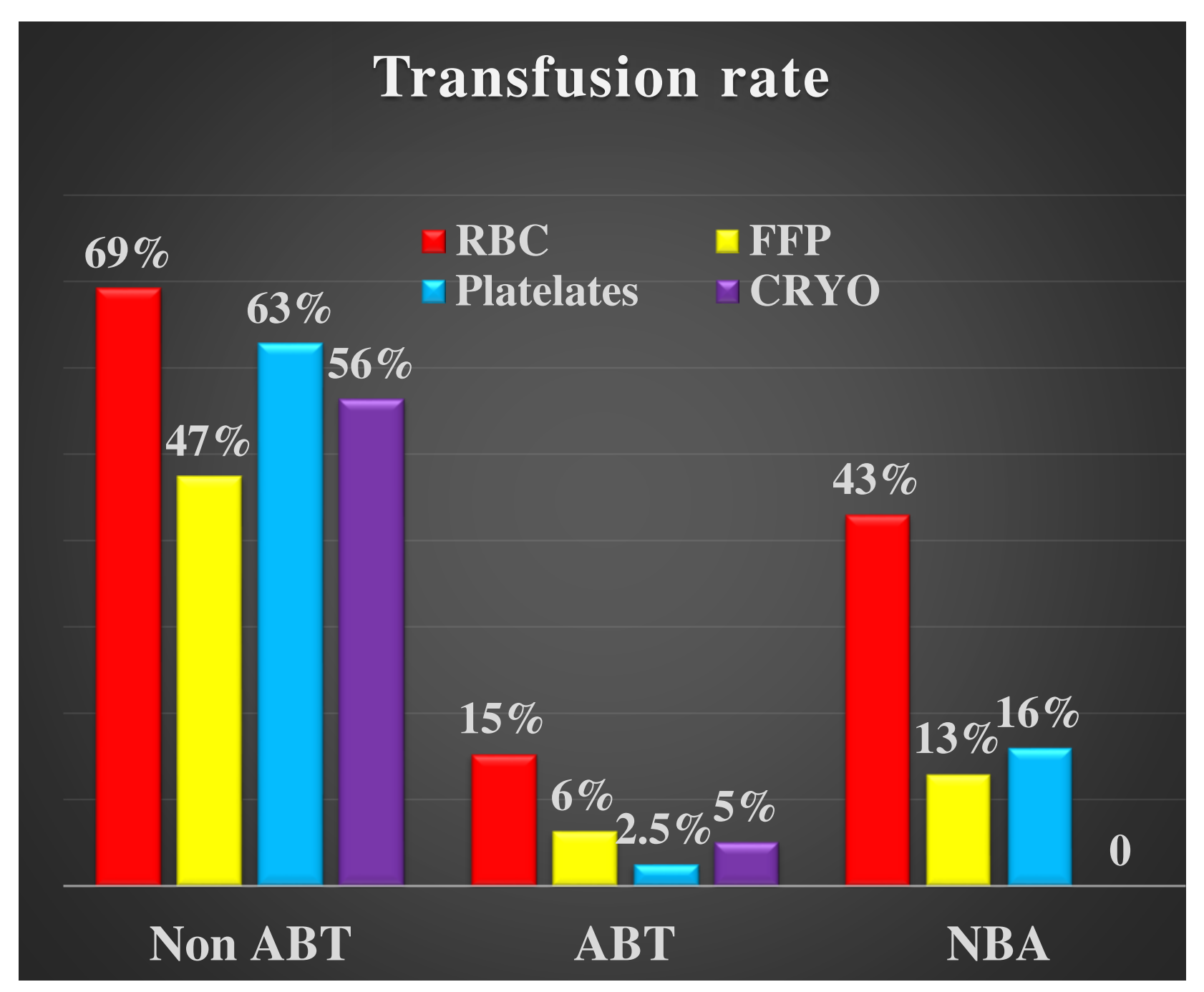

Conclusion: The overall transfusion rates are significantly less in patients with autologous blood donor group. Homologous blood transfusion can have adverse effects on clinical outcomes. Patients undergoing urgent or emergency coronary artery bypass grafting (CABG) are usually on single or dual antiplatelet agents, this is associated with increased need for homologous blood transfusion perioperatively. Autologous blood donation significantly reduces allogeneic blood requirement in cardiac surgery.

We recommend Autologous blood donation should be considered as a cost-effective and safe alternative to reduce allogenic blood consumption.

\section{References:}

1. Tinegate et al. Ten-year pattern of red blood cell use in the North of England. Transfusion2013

2. Grant-Casey J. Audit of blood transfusion in adult cardiac surgery, 2011. 